\title{
A SNAPSHOT OF ENGINEERING EDUCATION IN CANADA
}

\author{
Nancy Nelson, Robert Brennan \\ Schulich School of Engineering, University of Calgary \\ nancy.nelson1@ucalgary.ca rbrennan@ucalgary.ca
}

\begin{abstract}
Although all accredited engineering programs in Canada are assessed by the same governing body, each institution has its own set of expectations regarding its distribution of effort, the types of research conducted by its faculty, and the way it delivers its curriculum. Individual departments and programs each have their own strengths and challenges, but collectively they share the responsibility of educating tomorrow's engineers.

This paper presents a summary of the results of a descriptive study examining three aspects of engineering education in Canada: the balance and types of research, teaching, and service that engineering educators are doing, the level to which engineering educators are engaging with engineering education research, and the look and feel of the learning environment that undergraduate engineering students experience in accredited engineering programs in Canada.
\end{abstract}

Keywords: engineering education; distribution of effort; engineering education research; discipline-specific education research; teaching

\section{INTRODUCTION}

The success or failure of an undergraduate experience depends on the interaction of three key elements: the curriculum, the instructors, and the students [1]. Aspects of the engineering curriculum are dictated by regulatory bodies, and decisions around the actual content delivered are made at the program-level. Student demographics are constantly evolving [2], but delivery and activities in the engineering classroom appear to be unchanged [3][4][5].

Educators have both intrinsic and extrinsic factors governing the decisions they make around their teaching, research, and service to the institution and community. This paper aims to define some of these factors that help shape today's undergraduate engineering experience in Canada.

\section{BACKGROUND}

Since before confederation, engineering has been integral to the development of Canada as a nation. Defined as the act of "planning, designing, composing, evaluating, advising, reporting, directing or supervising, or managing any of the foregoing, that requires the application of engineering principles and that concerns the safeguarding of life, health, property, economic interests, the public welfare or the environment" [6], engineering established Canada's transportation, fortification, and infrastructure. Regulation of the profession began in 1886 and has grown to include the 12 engineering regulatory bodies that make up Engineers Canada today.

\subsection{Engineering Education in Canada}

In 1854, King's College in New Brunswick (now University of New Brunswick) offered the first formalized engineering program in Canada. 26 students enrolled in the two and a half month program. By the turn of the $20^{\text {th }}$ century there were six engineering schools offering programs in mechanical, civil, mining, and electrical engineering [7]. Today there are 43 institutions offering 281 accredited engineering programs across Canada.

Formalized accreditation of these programs began in 1965. With the goal of ensuring graduates meet the high standards necessary to become licensed professional engineers, the Canadian Engineering Accreditation Board (CEAB) initially reviewed the depth and breadth of mathematics, natural sciences, engineering sciences, engineering design, and complementary studies. This has been expanded to assess the level to which graduates demonstrate 12 graduate attributes related to their discipline-specific knowledge and skills, their employability, and their preparedness for professional practice. A continual improvement process is required to ensure ongoing quality of the program.

Introduction of graduate attributes has caused many accredited programs to reevaluate the way undergraduate engineering curriculum is organized and delivered. Organizations like CDIO (Conceive-Design-ImplementOperate) suggest that a move to integrated, authentic learning experiences will help shape graduates who are well-prepared for careers as practicing engineers [8]. Many programs have increased the number of designbased project courses in the curriculum, and some have moved to project-based or problem-based designs [9][10][11][12]. Change, however, cannot be effected 
without significant effort on the part of program administrators and faculty.

\subsection{Distribution of Effort}

Each post-secondary institution has a set of procedures pertaining to the appointment, promotion, and tenure of its academic staff. These procedures define expectations around teaching, research, and service, and often include a suggested Distribution of Effort (DoE) that is in line with the vision and strategic plan of the institution.

An examination of the tenure and promotion policies of 44 Canadian universities shows a number of trends and commonalities [13]. The majority of universities have a single set of tenure-track policies, with some accounting for a teaching-stream rank where an academic's responsibilities lie predominately within the teaching and service area, with a requirement to maintain currency in their discipline and/or be involved in the scholarship of teaching and learning. Typically, in the tenure-track path, the criteria for research contributions are more stringent and more articulately defined that those for teaching and service, although that seems to be changing. Most institutions require faculty to demonstrate "competence" in teaching and "excellence" in research [13], while the service component is less specific. There were no data reported on the expected DoE within these institutions, but some institutions separately report a more flexible distribution, allowing academic staff to engage in education-related research in addition to, or in lieu of, discipline-specific research [14].

An American 2014 descriptive study called Time Allocation Workload Knowledge Study (TAWKS) examined faculty work patterns and productivity [15]. It reported that faculty spent $30 \%$ of their time on activities not considered part of the traditional DoE (meetings at $17 \%$ and e-mail at 13\%). It is expected that this finding is similar to what most academics experience.

\subsection{Engineering Education Research}

An Institute for Electrical and Electronic Engineers (IEEE) study identified the application of education, learning, and social-behavioral sciences research as one of the five key shifts in engineering education over the last 100 years [16]. There is, for example, much to learn about instructional strategies and methods that could help ensure that the undergraduate engineering experience is conducive to learning.

Instructional strategies can be categorized into five main areas: (1) direct instruction, (2) indirect instruction, (3) experiential learning, (4) independent studies, and (5) interactive instruction [17]. Direct instruction is generally teacher-directed, where content is presented and then reinforced with examples. Indirect instruction is more student-centred and flexible. Students are encouraged to observe, investigate, draw inferences, and solve problems. Experiential learning is active and student-centred where learning is considered to be a five-phase cycle: experiencing, sharing, analyzing, inferring, and applying. Independent study activities are designed to make learners more responsible and accountable for their own learning, while interactive instruction relies on the discussion of ideas, experiences, knowledge, and insights with peers and instructors to establish alternative ways of viewing a concept.

Although Engineering Education Research (EER) is still considered to be in its infancy [18], and the number of research studies examining ways to improve learning is increasing, engineering educators often make changes to their teaching and/or the learning experience for their students without the influence and/or knowledge of EER [19]. Even though a Survey of Canadian Engineering Instructors (SCEI) was conducted in 2015 with 168 engineering educators at eight of the institutions sampled in this study [20], it is still difficult to identify exactly what is being done within the Canadian engineering education community.

This research seeks to remedy that by capturing a snapshot of what engineering education is like in Canada in 2018. It identifies the current balance and types of research, teaching, and service that engineering educators are doing, the level to which engineering educators are engaging with engineering education research, and the look and feel of the learning environment that undergraduate engineering students experience in accredited engineering programs in Canada.

\section{METHODOLOGY}

An e-mail was sent to 3376 engineering educators inviting them to complete an online survey entitled 'A Snapshot of Canadian Engineering Education'. Some institutions provided the researchers with a mailing list of their faculty, others were contacted directly via the e-mail posted on their departmental web site, and a third group were contacted through their on-campus member of GANet, an online network of engineering faculty and staff involved in the engineering accreditation process. There were no incentives provided for engineering instructors to complete the survey.

The survey was modeled after the Higher Education Quality Council of Ontario (HEQCO) survey on faculty engagement in teaching development activities [21] and a Faculty Focus informal survey of post-secondary educators examining teaching challenges [22]. The snapshot survey was divided into three main sections: (1) Demographics, (2) Institutional Expectations and (3) Undergraduate Engineering Education.

\section{RESULTS}

Of the 3376 engineering educators contacted, 218 participated in this research study $(6.3 \%)$. There was representation from $74.4 \%$ of the institutions that offer 
accredited engineering programs. Contact information was not available for educators at two institutions (University of Moncton and University of Quebec), so they were not contacted and, unless they received an invitation to participate from a colleague in one of the other accredited engineering programs, did not contribute to these results.

There is a possibility that the findings of this survey have a bias associated with non-response. Those who chose to complete this survey may have different views from those who did not. This may limit the generality of the results of this study [23][24]. It is also not known to what degree respondents were encouraged to participate by their institution's administration, or what other factors may have contributed to their response or non-response. As a result, the following findings should be considered with caution.

\subsection{Demographics}

The results show that the majority of respondents (43.9\%) have been teaching for between five and 15 years. The next largest group (39.2\%) includes the instructors who have been teaching for more than 15 years, with the remaining $17.0 \%$ being new faculty with fewer than five years' teaching experience.

\subsection{Distribution of Effort}

Most participants reported the expected distribution of effort (DoE) between research, teaching, and service to be $40(59.7 \%)(M=34.9, S D=15.6), 40(61.2 \%)(M=44.3$, $S D=15.9)$, and $20(70.9 \%)(M=35.5, S D=21.0)$. The actual DoE indicates that, while time spent teaching is quite close to the expected $(M=38.8, S D=18.9)$, time spent in service $(M=26.5, S D=17.3)$ seems to detract from time available for research $(M=35.5, S D=21.0)$. Figure 1 compares the expected and actual DoE.

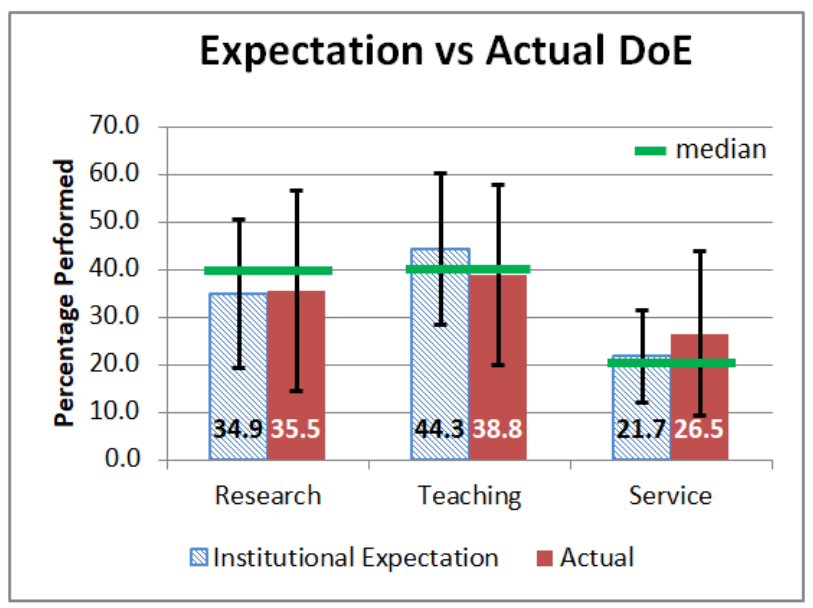

Figure 1: Distribution of effort - expectation vs. actual

When asked to report on the types of disciplinespecific research participants were pursuing, the vast majority of their primary research was technical in nature (95.6\%). 3.2\% identified engineering education research as a primary area of research, and $1.2 \%$ indicated engineering design. When asked specifically about their involvement with design and/or engineering education research, $42.8 \%$ indicated some level of involvement with design, and $47.1 \%$ with EER. $81.3 \%$ reported they are doing some form of applied research that supports the efforts of industry.

Participants, on average, teach fewer than four courses per academic year $(M=3.4, S D=1.3)$. Approximately one is at the first year level $(M=0.7, S D=1.2), 2$ in upper years of an undergraduate program $(M=2.2, S D=$ $1.3)$, and one in graduate studies $(M=0.9, S D=0.6)$.

When asked to rank how important they believed teaching was to their institution when being evaluated for their performance review, participant responses ranged from 0 (not important at all) to 100 (extremely important). The average response was $60.9(S D=26.0)$. The majority (40.4\%) ranked the importance less than 50\%. $33.9 \%$ ranked it between 76 and $100 \%$, with the remaining $25.7 \%$ between $51 \%$ and $75 \%$.

The ways in which participants contribute to their program, school, or institution are shown in Figure 2. The most frequent methods of contribution were working on committees beyond their program (68.5\%), and participating in curriculum design and/or review $(67.4 \%)$. The smallest participation is in provincial or national engineering governance or regulatory activities (15.8\%). Other service contributions reported by the respondents included advising individual students and student groups, editing journals, participation in faculty organizations and/or union management, organizing conferences, and industrial liaison.

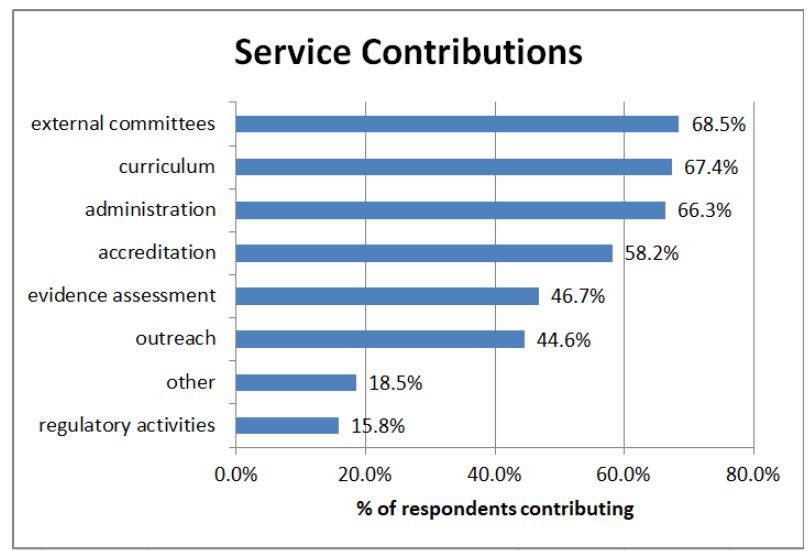

Figure 2: Service contributions

Figure 3 shows that the majority of the participants $(65.5 \%)$ believe the introduction of graduate attributes as part of the accreditation process has had a moderate to major effect on their workload. $5.4 \%$ believe it has had no effect on their workload. 


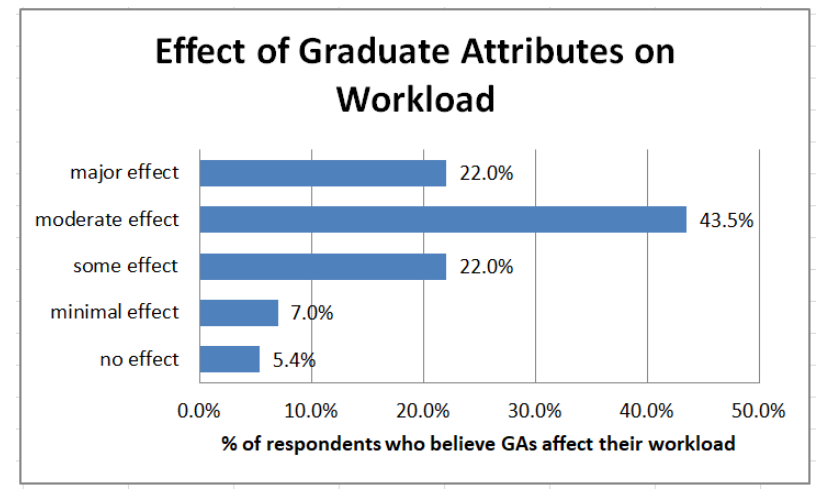

Figure 3: Effect of graduate attributes on workload

\subsection{Engagement within Engineering Education Research}

Respondents identified that they participate in an average of $2(S D=2.0)$ different types of professional development (PD) activities in a given academic year. Figure 4 shows the most common types of PD are discipline-specific conferences or workshops (76.1\%), and local or in-house discipline-specific presentations or workshops $(57.8 \%)$. Almost half of the respondents indicated they attend local or in-house sessions on teaching and learning (43.3\%), and approximately $20 \%$ attend engineering education conferences $(22.8 \%)$ and teaching and learning conferences (19.4\%). Other PD activities identified by participants included user groups, Massively Open Online Courses (MOOCs), online courses, self-directed learning, and leadership workshops.

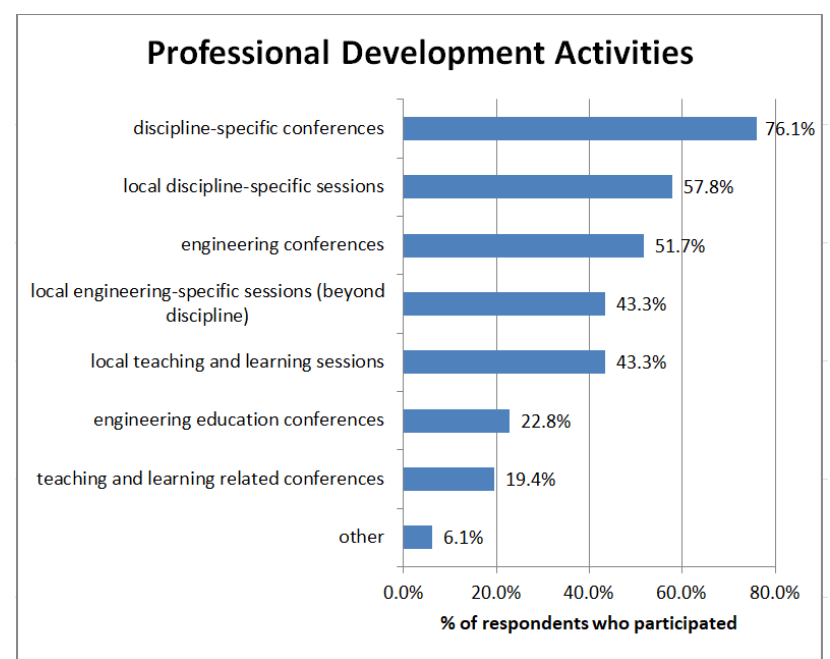

Figure 4: Professional development activities

Overall, the PD activities of the respondents were more discipline-related than teaching-related. In order to get a sense of how engaged participants were with EER, further questions explored professional development activities specifically related to their teaching.

The ways by which participants learned to teach at the beginning of their career are reported in Figure 5. The majority learned by doing (93.6\%). Some learning resulted from informal discussions with peers $(69.9 \%)$, and $13.9 \%$ learned through brown bag lunch session on teaching. Respondents who indicated 'other' gained their experience by using other resources offered by their teaching and learning centres, through education-related degrees, reflections on student feedback, emulating peers, online education-related resources, and self-study.

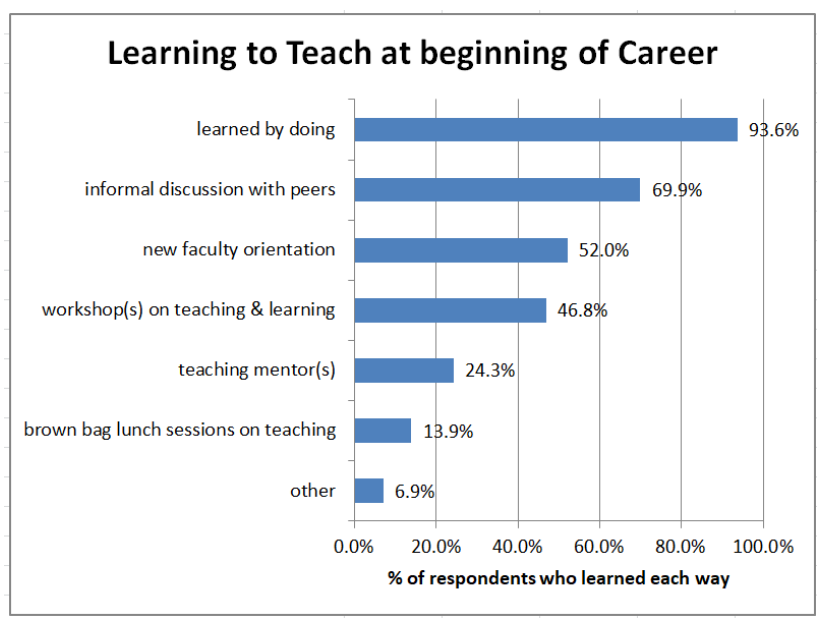

Figure 5: Learning to teach at beginning of career

The ways by which participants keep their teaching skills current are shown in Figure 6. The majority continue to learn by doing $(95.3 \%)$, some rely on consultation with colleagues $(69.2 \%)$, and $11.0 \%$ had a mentor to whom they could turn. Respondents who indicated 'other' stay current by reflecting on student feedback, consulting with colleagues at other institutions, using "teaching wheels", a small group of teachers who work collaboratively to address questions and concerns about their teaching [25], participating in accreditation reviews of other programs, and learning about new classroom technologies.

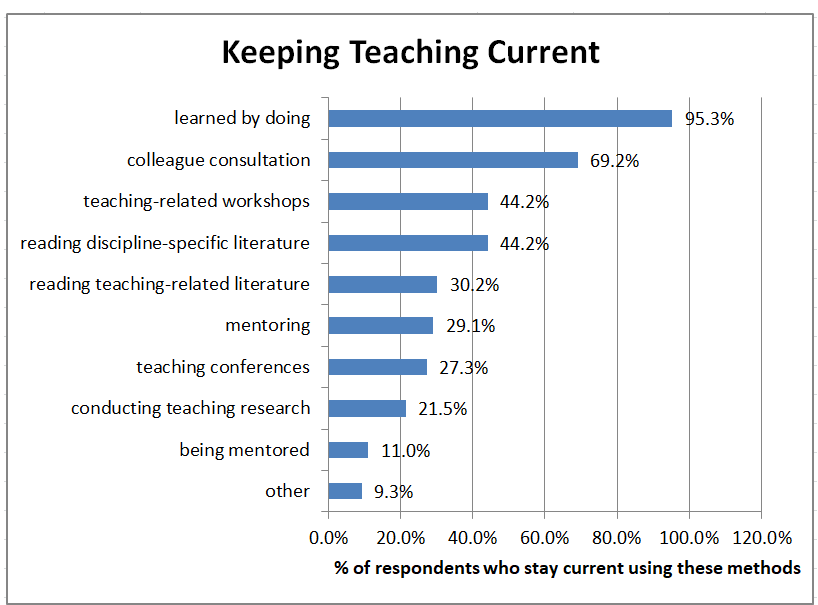

Figure 6: Staying current in one's teaching 
Looking specifically at the activities related to EER there appears to be an increased interest in learning about teaching. A higher percentage $(44.2 \%)$ of respondents participate in teaching-related workshops or seminars compared to those surveyed in the 2010 HEQCO faculty engagement study (37.2\%) [21], and the SCEI survey (31\%) [20]. The percentage of instructors whose teaching practice is informed by published education-related research $(30.2 \%)$ is similar to both the HEQCO (30.3\%) and SCEI (29\%) findings. The percentage of participants who are involved education-related research $(21.5 \%)$ is slightly higher than the HEQCO (18.3\%) results (no results reported in SCEI).

Figure 7 shows that the majority of participants $(83.7 \%)$ put a strong or very strong emphasis on their teaching. This is slightly lower than the $95.7 \%$ of HEQCO respondents who reported that teaching was important or very important to their overall professional practice. Figure 8 shows that more than half of the participants $(59.1 \%)$ put a strong or very strong emphasis on continued development of their teaching skills. Only 9.3\% put little or no emphasis on continuing to develop their teaching skills.

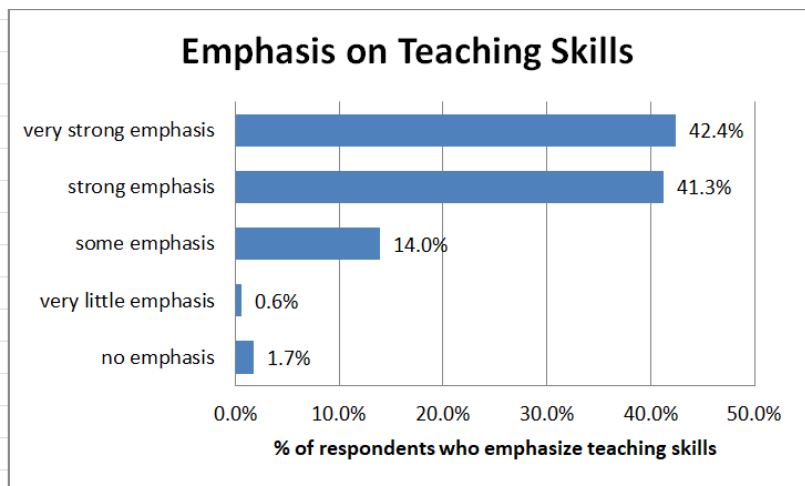

Figure 7: Personal emphasis on Teaching

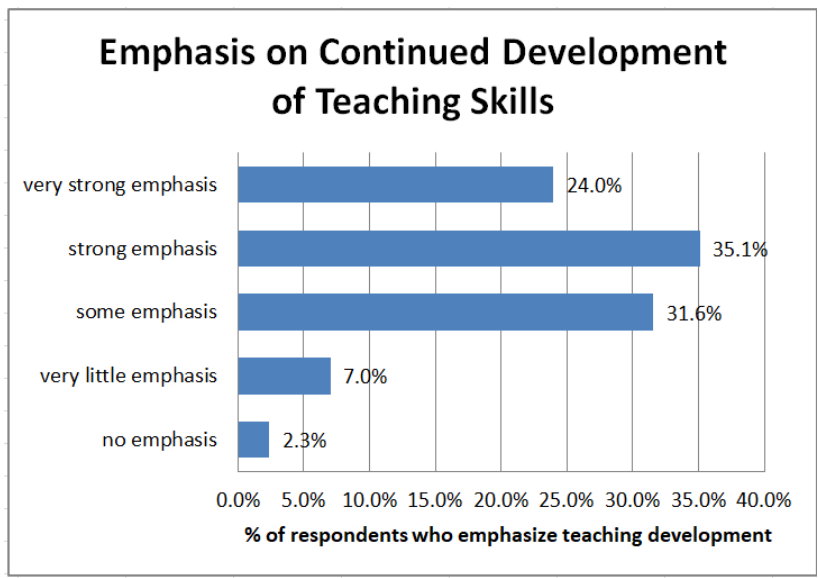

Figure 8: Emphasis on development of teaching skills

Figure 9 shows that $60.0 \%$ of the participants attend a workshop related to teaching and learning at least once or twice a year, slightly down from the $66.8 \%$ reported in the HEQCO study. $46.2 \%$ take advantage of the services offered by their teaching and learning centre (TLC) to learn about different teaching practices, techniques, or tools, which is also slightly down from HEQCO's $53.8 \%$. The $87.0 \%$ who use critical self-reflection at least once or twice a year is up from the $83.0 \%$ reported by HEQCO. $85.2 \%$ discuss teaching and learning with their colleagues at least once or twice a year, down from HEQCO'S $90.8 \%$. Mentors are consulted by $38 \%$ of the respondents compared to $48 \%$ of the HEQCO participants. Those who identified other forms of teaching-related PD noted discussing teaching with students, relying on feedback from trusted students, and using their TLC as required. One participant noted that since the teaching skills of tenured professors are not evaluated, teaching-related PD "doesn't really matter".

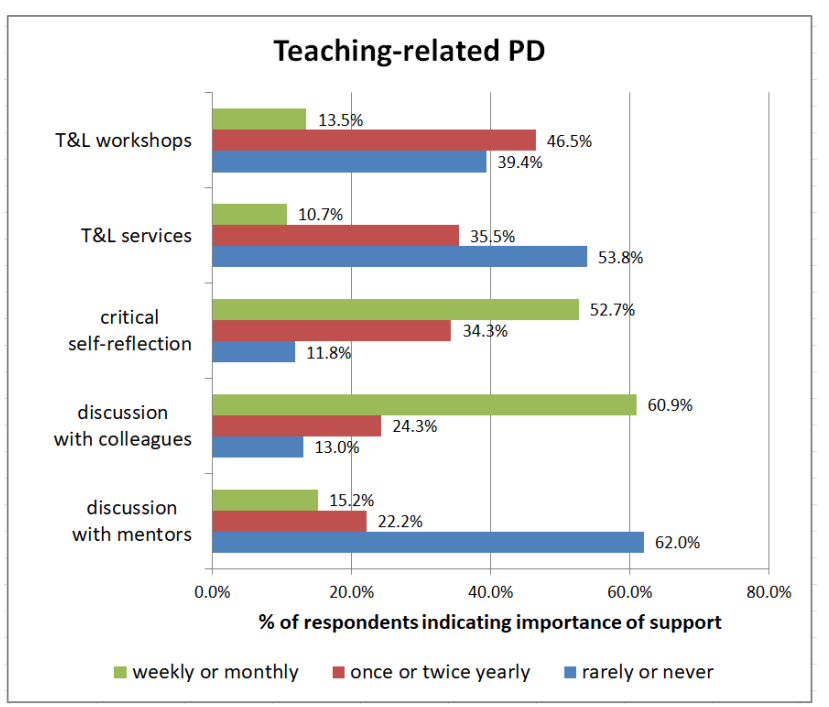

Figure 9: Participation in teaching-related PD

Figure 10 shows that $60.1 \%$ of the participants make use of the information, services, and/or resources provided by their institution's TLC to help with their teaching $(60.1 \%) .50 .6 \%$ use the resources one to four times per year, down from HEQCO's $77.5 \%$.

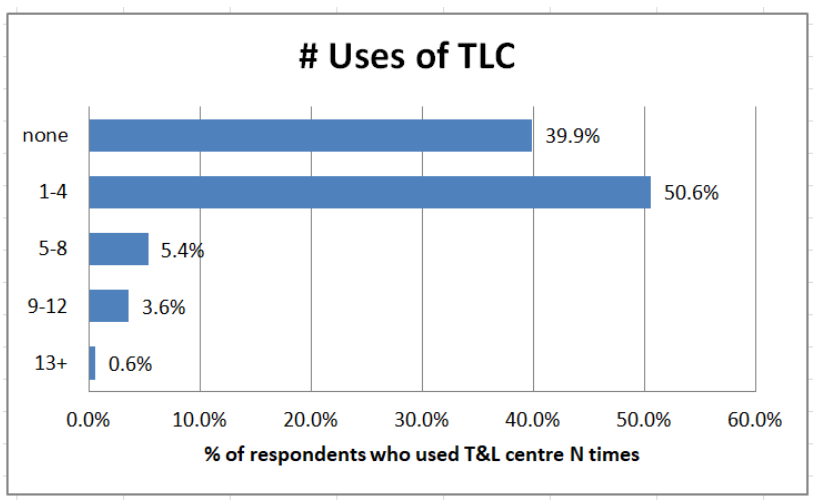

Figure 10: Number of times TLC used 
$66.3 \%$ of the participants make some use of teaching and learning related literature. As shown in Figure 11, slightly fewer participants make use of general teaching and learning literature (77.3\%) compared to those who use discipline-specific teaching and learning literature $(80.7 \%)$. These numbers are up significantly from the HEQCO study where $56.9 \%$ make use of general teaching and learning literature, and $63.0 \%$ use discipline-specific teaching and learning literature.

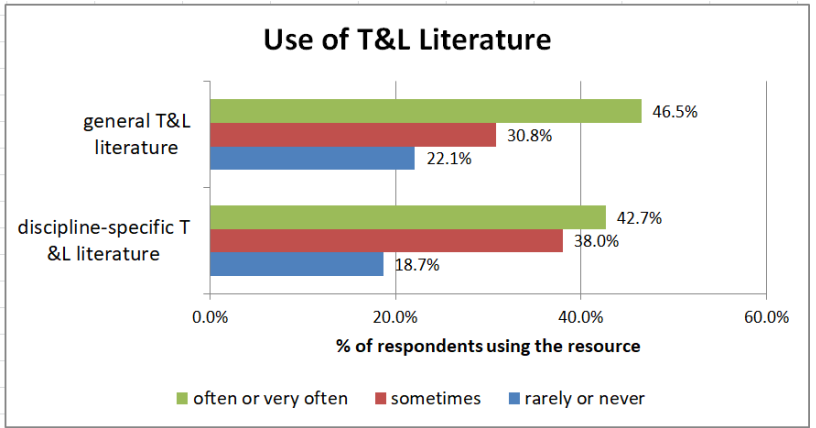

Figure 11: Use of teaching \& learning literature

$37.2 \%$ of the respondents indicated they had done either formal or informal research to explore classroomrelated issues including, but not limited to, student behaviour, change of student performance, use of new strategies, and use of new tools or techniques. 35.5\% indicated they had made changes in their classroom because of this work. $12.2 \%$ had received research ethics board approval for their work, and $18.0 \%$ had published or presented their results. These findings are down from those of the HEQCO study where of the less than half (no specific number reported) $71 \%$ had made changes in their classroom, and 29\% had shared results at conferences.

\subsection{Undergraduate Engineering Experience}

Figures 12 through 16 show that participants rely mainly on direct instruction methods in their classrooms, with the lecture far surpassing all other methods (95.3\%) and worked examples (79.7\%) supported by indirect instruction methods such as in-class exercises $(59.1 \%)$, and case studies $(50.0 \%)$. Concepts learned in these classes are reinforced with experiential learning labs or experiments $(80.7 \%)$, and independent study methods such as homework assignments (74.1\%) and research or design projects $(62.5 \%)$. Fewer than half of participants are using interactive instruction such as cooperative learning $(48.2 \%)$, peer instruction $(42.6 \%)$, or flipped learning $(32.1 \%)$ on a regular basis. Neither are many using non-traditional experiential learning methods such as games or gamification $(21.5 \%)$.

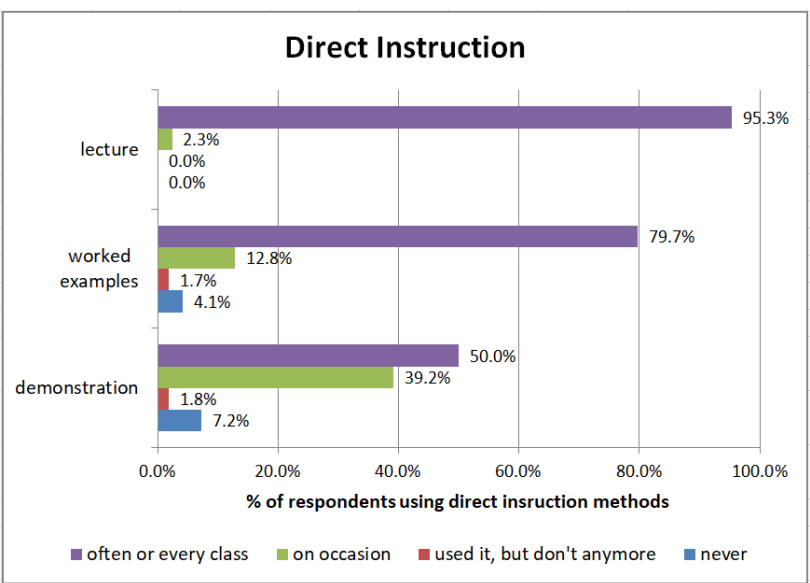

Figure 12: Use of direct instruction methods

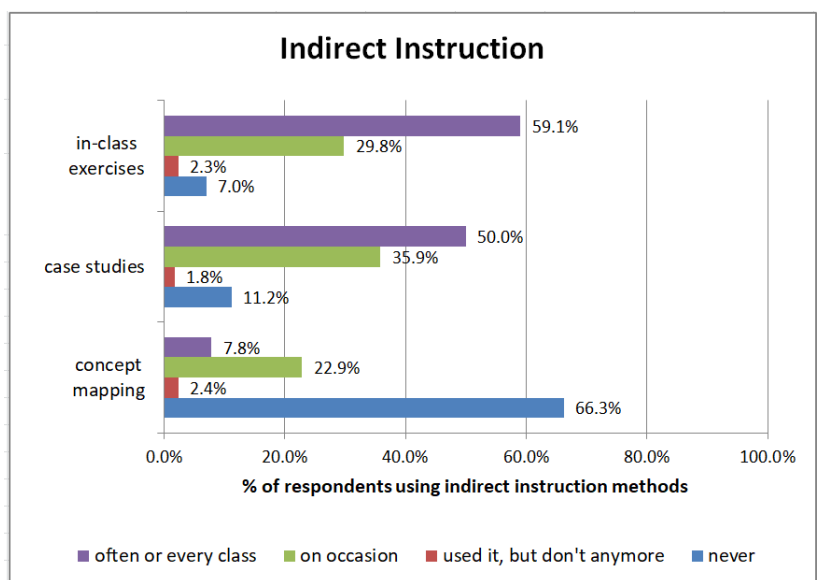

Figure 13: Use of indirect instruction methods

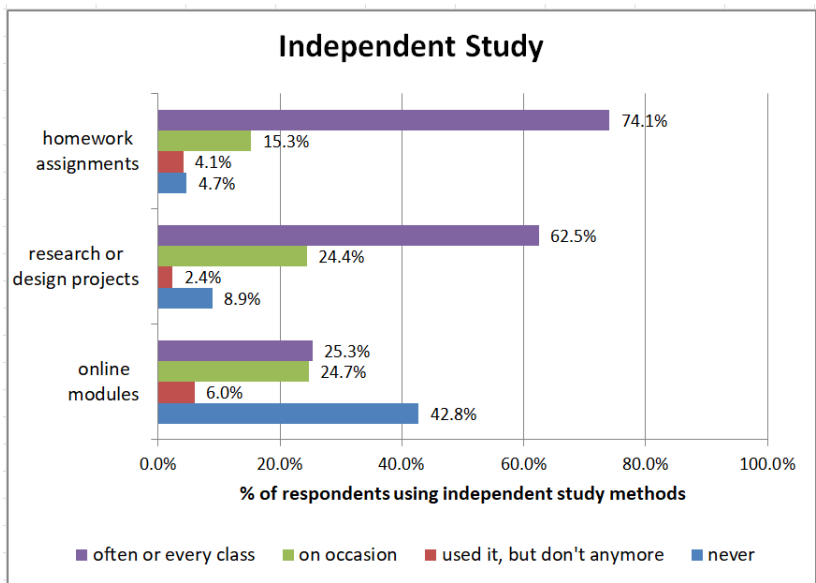

Figure 14: Use of Independent study methods 


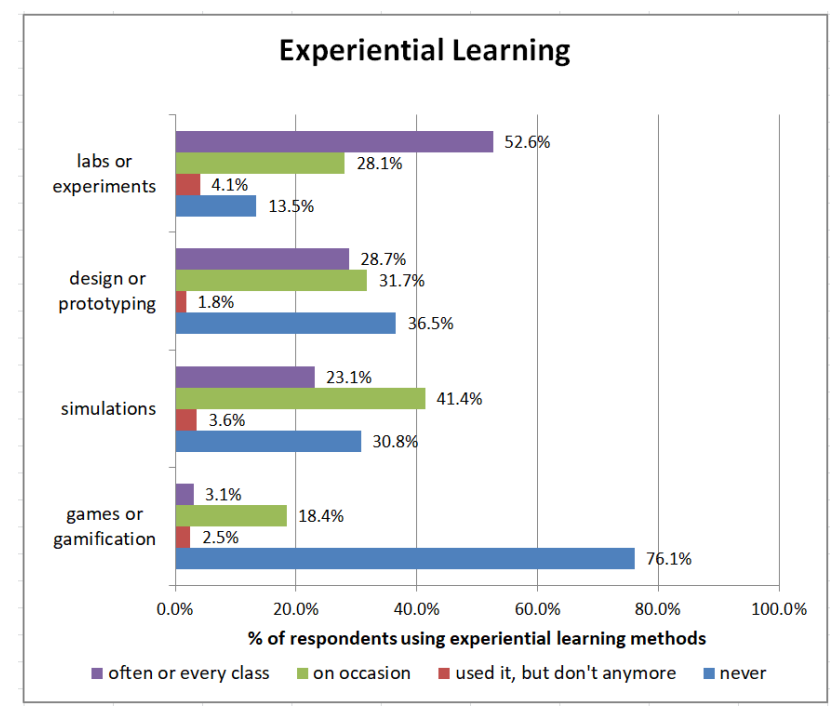

Figure 15: User of experiential learning methods

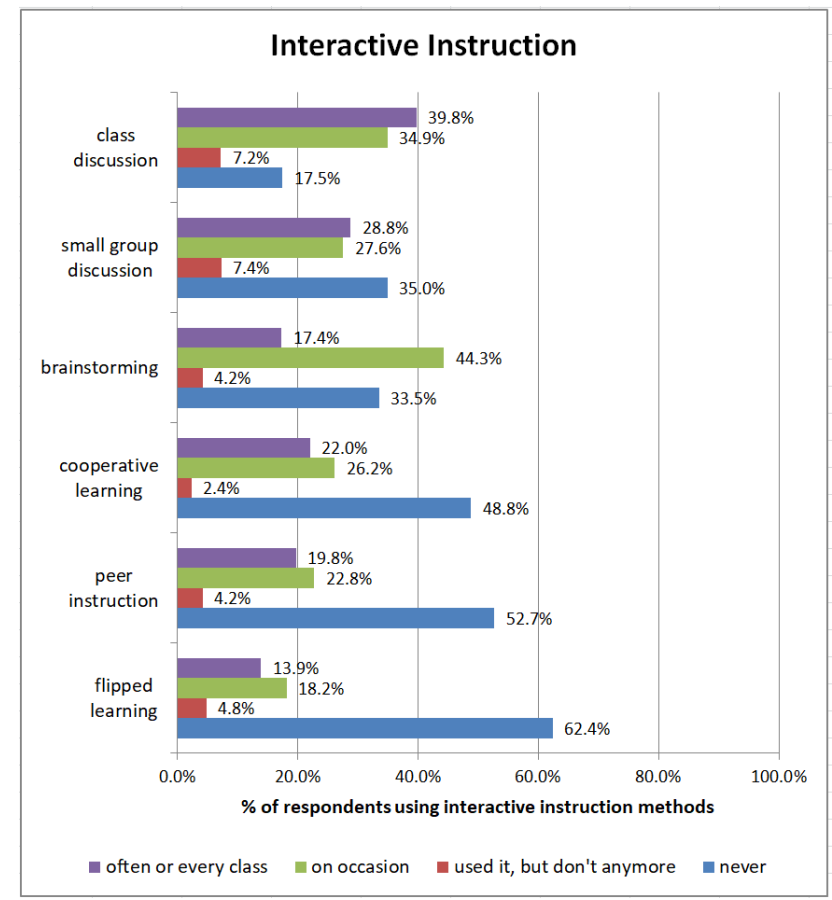

Figure 16: Use of interactive instruction methods

The most commonly used teaching tools are shown in Figure 17. PowerPoint or an equivalent (77.9\%), a white or black board $(70.8 \%)$, and their institution's Learning Management System (LMS) (62.0\%) top the list.

Respondents who stopped using tools they had tried were asked to explain why they had abandoned them. Answers ranged from student resistance and buy-in, negative comments on teaching evaluations, time commitment vs. overall benefit, dependency on studentprovided devices, health challenges, and limited access to tools in assigned classrooms.

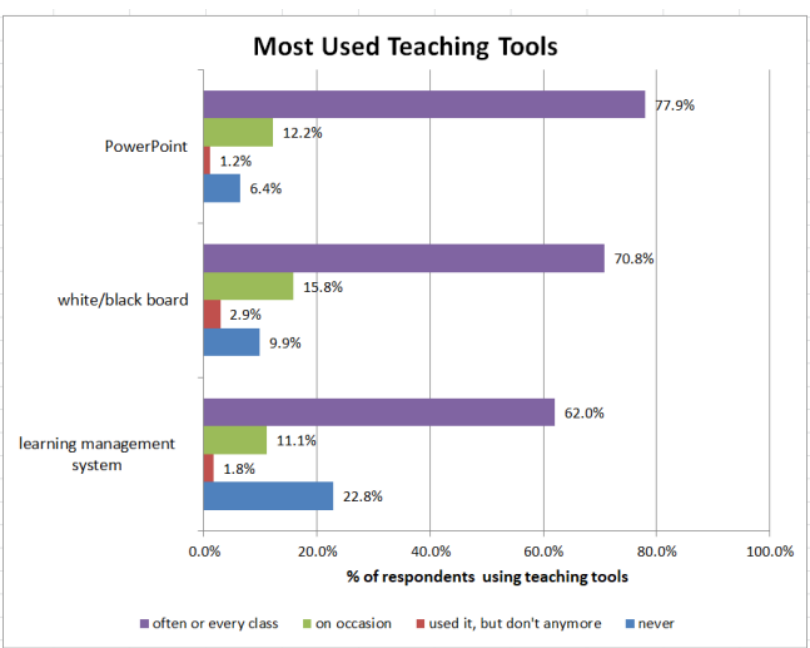

Figure 17: Most used teaching tools

Participants were asked to rank how problematic certain issues and challenges were in their day-to-day work. Figure 18 shows that the most problematic was the time required to grade papers, assignments, quizzes, and exams $(59.3 \%) .59 .1 \%$ of participants struggle to balance work and life, and $58.7 \%$ are concerned about students who are ill-prepared for the rigors of engineering. Increasing class sizes $(58.1 \%)$ and challenges associated with student motivation $(53.2 \%)$ round out the top five.

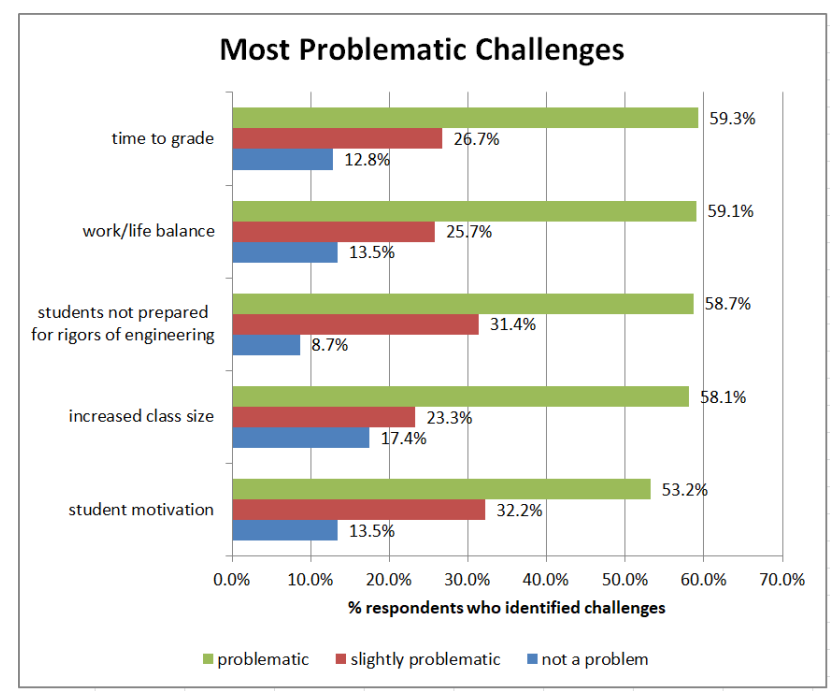

Figure 18: Most problematic challenges

Participants commented that students are more likely to struggle with school/life balance, there is a lot of absenteeism, and some of the students are getting aggressive, and ready to protest any statement. There is a sense that many students don't really know what engineering is all about, and by the time they get into the upper years where they are expected to apply math and science concepts, they start to question why they're in engineering. Comments also indicate a frustration with students who expect good grades for minimal effort. 
Comparing this study to the results of the Faculty Focus survey $(\mathrm{N}=1065)$ [22] identifies a noteworthy difference between the challenges faced by Canadian engineering educators and their global interdisciplinary colleagues. This study identified two student-related challenges in the top five (ill-prepared for the rigor and motivation), while four of the top five challenges identified in the Faculty Focus study were student-related: students who come to class unprepared $(63.4 \%)$, students who are not prepared for the rigor of their program (59.7\%), student motivation (49.0\%), and technology distractions (45.4\%).

Participants were also asked to compare the difficulty of their job today to what it was five years ago. $13.1 \%$ indicated their work is less difficult. $42.9 \%$ indicated it was the same, and $44.0 \%$ that it is now more difficult. Reasons given for the increase in difficulty included accreditation-related responsibilities, increasing class sizes, diversity, preparation, and motivation of students, changing tools, less administrative and teaching assistant support, and pressures related to research.

\subsection{General Comments}

Participants were offered the chance to include additional comments at the end of the survey. These were distributed across three main categories: teaching, DoE, and students. Participants indicated concern about low institutional prioritization of teaching and the effect on the classroom, the desire to invest more time focusing on their teaching, and the culture of 'how I teach is okay or good enough'. One respondent put it quite succinctly "In theory we should teach to pass, in practice we fail to teach.” There was mention that content should be stressed over delivery.

Participants indicated their time was spread thinly and the demands of their research often outweighed those of teaching. They identified frustration that changing leadership often brings different expectations around DoE.

Some felt that while students are still bright, focused, and engaged young people, they have become more strategic learners, valuing grades over learning. They often use technology to seek out and memorize "the recipe" from previous exams and assignments rather than using those resources to help find solutions to real problems. They can solve "cookie cutter" textbook questions, but cannot take a complex engineering situation, isolate the type of problem, and use appropriate tools to analyze and predict solutions.

Concern was identified around the need for innovation in the classroom, be it different instructional methods or the use of education technology. There was also concern raised about recruiting engineering education-focused faculty who are not also "real" engineering researchers and experts.

\section{DISCUSSION}

This study examined three aspects of engineering education in Canada: (1) the balance and types of research, teaching, and service that engineering educators are doing, (2) the level to which engineering educators are engaging with engineering education research, and (3) the look and feel of the learning environment that undergraduate engineering students experience in accredited engineering programs in Canada.

Canadian engineering educators report a distribution of effort fairly close to the institutional expectation. While the time allocated for teaching remains around 40\%, faculty tend to spend more than the expected $20 \%$ of their time on various forms of service at the expense of their research. The increased service time may be linked to the effect graduate attributes have had on their workload. This imbalance, plus the 'beyond-DoE' tasks identified in the TAWKS findings [15] (meetings and e-mail) may be a contributing factor to the clearly identified challenge of work/life balance.

Although the vast majority of research performed by engineering educators is discipline-specific, a growing number of instructors have some level of involvement with engineering education research. While participation sits around $20 \%$, there does not seem to be any notable difference between engineering educators' level of engagement with EER and that their interdisciplinary peers have with the Scholarship of Teaching and Learning (SoTL) or Discipline-Based Education Research (DBER). There does appear to be an increasing interest in learning about teaching and learning which may in turn spark increased involvement with, and contribution to the EER body of work in Canada.

These results show that, while Canadian engineering educators believe their institution places a middling value on teaching, they themselves put a strong emphasis on their teaching. Most participate in some form of teachingrelated PD at least once a year, and almost half make use of general or discipline-specific teaching and learning resources. That said, most of the undergraduate engineering experience is grounded in teacher-directed instruction using traditional teaching methods and tools. This concurs with the findings of studies that show evidence-based instructional strategies are making it into very few classrooms [26][3][4][27][5]. Potential barriers include, but are not limited to, workload, time, student attitude, institutional reward system, content coverage, and availability of resources [26][20][28]. There are opportunities for growth however, if the $25 \%$ of engineering educators who place a strong emphasis on teaching but not the continued development of their teaching skills can be convinced of its value.

The general comments seem to indicate that Canadian engineering educates care about their research, their teaching, and their students. Through careful balancing of 
our research, teaching, and service, our community of engineering educators can collectively work to strengthen the undergraduate experience of tomorrow's engineers.

\section{FUTURE WORK}

There are a number of avenues for future work resulting from this study. First, an attempt could be made to reduce the possible effects of the non-response bias by reiterating the request for Canadian engineering educators to complete the survey. The collected data could be analyzed to determine if there are significant relationships between the sample's demographics, the distribution of effort, engagement with engineering education research, and the undergraduate engineering experience. The open ended responses could also be analyzed to identify common areas of concern to explore.

Future work could also examine the effect that changes to the engineering accreditation process, including the introduction of graduate attributes and the continual improvement process, are having on instructors' overall workload and expected service contribution.

Finally, further work could be done to identify ways to reach and encourage the core of educators who place importance on their teaching, but are not investing in the ongoing development of their teaching skills.

\section{Acknowledgements}

This research study is funded by the National Sciences and Engineering Research Council of Canada (NSERC) and approved by the University of Calgary Conjoint Faculties Ethics Board. Special thanks to the engineering educators who took the time to complete this survey, and the peer reviewers for their time and invaluable feedback.

\section{References}

[1] M. Prosser and K. Trigwell, "Qualitative variation in approaches to university teaching and learning in large first-year classes," High. Educ., vol. 67, no. 6, pp. 783795, 2014.

[2] C. Seemiller and M. Grace, Generation Z goes to college. San Francisco: Jossey-Bass, 2016.

[3] S. R. Singer, N. R. Neilsen, and H. A. Schweingruber, Discipline-Based Education Research: Understanding and Improving Learning in Undergraduate Science and Engineering. Washington, DC: National Academies Press, 2012.

[4] J. E. Froyd, M. Borrego, S. Cutler, C. Henderson, and M. J. Prince, "Estimates of use of research-based instructional strategies in core electrical or computer engineering courses," IEEE Trans. Educ., vol. 56, no. 4, pp. 393-399, 2013.

[5] M. Dancy, C. Henderson, and C. Turpen, "How faculty learn about and implement research-based instructional strategies: The case of Peer Instruction," Phys. Rev.
Phys. Educ. Res., vol. 12, no. 1, pp. 1-17, 2016.

[6] "National guideline on the practice of engineering in Canada," Ottawa, 2012.

[7] G. A. Morris, "Engineering education in Canada: the early years," Can. J. Civ. Eng., vol. 13, pp. 25-32, 1986.

[8] E. F. Crawley, J. Malmqvist, S. Östlund, and D. R. Brodeur, Rethinking Engineering Education, 2nd ed. Switzerland: Springer International Publishing, 2014.

[9] D. R. Woods, "Problem-based learning for large classes in chemical engineering," New Dir. Teach. Learn., vol. 68, no. 68, pp. 91-99, 1996.

[10] D. Bédard, C. Lison, D. Dalle, D. Côté, and N. Boutin, "Problem-based and Project-based Learning in Engineering and Medicine: Determinants of Students' Engagement and Persistance," Interdiscip. J. Probl. Learn., vol. 6, no. 2, pp. 8-22, 2012.

[11] N. Nelson, "Achieving graduate attributes through project-based learning," in Proceedings of the CEEA 2014 5th Annual Conference, 2014, pp. 1-7.

[12] R. Gonzalez-Rubio, A. Khoumsi, M. Dubois, and J. P. Trovao, "Problem- and Project-Based Learning in Engineering: A Focus on Electrical Vehicles," 2016 IEEE Veh. Power Propuls. Conf. VPPC 2016 - Proc., 2016.

[13] P. Gravestock and E. G. Greenleaf, "Overview of Tenure and Promotion Policies Across Canada," Unpubl. Pap. Univ. Toronto, pp. 1-5, 2008.

[14] N. Kenny, G. P. L. Watson, and S. Desmarais, "Building Sustained Action: Supporting an Institutional Practice of SoTL at the University of Guelph," New Dir. Teach. Learn., no. 146, pp. 87-94, 2009.

[15] J. Ziker, "The Long, Lonely Job of Homo academicus: Focusing the research lens on the professor's own schedule," 2014. [Online]. Available: https://thebluereview.org/faculty-time-allocation/. [Accessed: 08-Feb-2018].

[16] J. E. Froyd, P. C. Wankat, and K. A. Smith, "Five major shifts in 100 years of engineering education," Proc. IEEE, vol. 100, no. SPL CONTENT, pp. 13441360, 2012.

[17] Saskatchewan Education, "Instructional Approaches: A Framework for Professional Practice," Regina, Saskatchewan, 1991.

[18] M. Borrego, M. J. Foster, and J. E. Froyd, "Systematic literature reviews in engineering education and other developing interdisciplinary fields," J. Eng. Educ., vol. 103, no. 1, pp. 45-76, 2014.

[19] R. M. Felder and R. G. Hadgraft, "Educational Practice and Educational Research in Engineering: Partners, Antagonists, or Ships Passing in the Night?," J. Eng. Educ., vol. 102, no. 3, pp. 339-345, 2013.

[20] J. Kaupp et al., "The Canadian Engineering Education 
Association Research Collaboration (CEEA-RC): Annual Survey of Canadian Engineering Instructors," CEEA Conf. Proc. 2015, pp. 1-12, 2015.

[21] J. Britnell et al., "University faculty engagement in teaching development activities Phase 2," 2010.

[22] M. Bart, "Reader Survey Finds Unprepared Students a Persistent Problem," Faculty Focus, 2016. [Online]. Available:

https://www.facultyfocus.com/articles/teaching-andlearning/reader-survey-finds-unprepared-studentspersistent-problem/. [Accessed: 07-Feb-2018].

[23] L. J. Sax, S. K. Gilmartin, and A. N. Bryant, "Assessing Response Rate and Nonreponse bias in Web and Paper Surveys," Res. High. Educ., vol. 44, no. 4, pp. 409-432, 2003.

[24] K. A. Adams and E. K. Lawrence, Research Methods, Statistics, and Applications, 1st ed. Thousand Oaks, California: SAGE Publications, 2015.
[25] P. Hutchings, Making Teaching Community Property: A Menu for Peer Collaboration and Peer Review. AAHE Teaching Initiative, 1996.

[26] C. Henderson and M. H. Dancy, "Barriers to the use of research-based instructional strategies: The influence of both individual and situational characteristics," Phys. Rev. Spec. Top. - Phys. Educ. Res., vol. 3, no. 2, pp. 114, 2007.

[27] H. J. McLaren and P. L. Kenny, "Motivating change from lecture-tutorial modes to less traditional forms of teaching," Aust. Univ. Rev., vol. 57, no. 1, pp. 26-33, 2015 .

[28] T. A. Litzinger, L. R. Lattuca, R. G. Hadgraft, and W. C. Newstetter, "Engineering Education and the Development of Expertise," J. Eng. Educ., vol. 100, no. 1, pp. 123-150, 2011. 